\title{
Análise multitemporal do uso da terra municipal em Assis Chateaubriand, Paraná
}

\section{Multitemporal analysis of the use of municipal land in Assis Chateaubriand, Paraná}

Análisis multitemporal del uso de la tierra municipal en Assis Chateaubriand, Paraná

Luciana Virginia Mario Bernardo ${ }^{1}$ Ricardo Rippel ${ }^{2}$ Maycon Jorge Ulisses Saraiva Farinha ${ }^{3}$ Adelsom Soares Filho ${ }^{4}$

${ }^{1}$ Doutora em Desenvolvimento Regional e Agronegócios pela Universidade Estadual do Oeste do Paraná (UNIOESTE). E-mail:lucianamario@yahoo.com.br, ORCID: http://orcid.org/0000-0001-7615-0433

${ }^{2}$ Doutor em Demografia pela Universidade Estadual de Campinas (UNICAMP).E-mail: ricardo_rippel@yahoo.com.br, ORCID: https://orcid.org/0000-0003-0934-0979

${ }^{3}$ Doutorando em Geografia pela Universidade Federal de Grande Dourados (UFGD). E-mail: maycondds@hotmail.com, ORCID: https://orcid.org/0000-0001-9405-2511

${ }^{4}$ Doutor em Ciências pela Universidade Estadual de Campinas (UNICAMP). E-mail: adelsomfilho@ufgd.edu.br, ORCID: https://orcid.org/0000-0003-0433-5732 
Resumo: $O$ objetivo do estudo é analisar as mudanças no uso da terra no município de Assis Chateaubriand, Paraná, no período de 1985 a 2017, a partir do modelo shift-share. A colonização do município de Assis Chateaubriand foi constituída de diferentes interesses que possibilitaram a sua colonização, entre eles, o uso de recursos naturais, como o uso da terra. Para a realização do estudo, foram utilizados o modelo shift-share, o processamento de imagens e a avaliação qualitativa da paisagem. Entre os resultados identificados, poucas alterações foram observadas no uso da terra, mantendo a predominância do uso da terra agrícola. Contudo as mudanças na produção agrícola foram alteradas no decorrer do tempo; atualmente, há predominância produtiva de culturas temporárias, o que possibilitou a homogeneização da paisagem.

Palavras-chave: mudanças no uso da terra; análise local; shift-share.

\begin{abstract}
The study aims to analyze the changes in land use in the municipality of Assis Chateaubriand, Paraná state, from 1985 to 2017, using the shift-share model. The colonization of the Assis Chateaubriand municipality was made up of different interests that enabled its colonization, among them, the natural resources use, such as land use. To carry out the study, we used the shift-share model, image processing, and qualitative landscape assessment. Among the results identified, few changes were observed in land use, maintaining the predominance of agricultural land use. However, changes in agricultural production have changed over time. There is a predominance, nowadays, of temporary crops, which enabled the homogenization of the landscape.
\end{abstract}

Keywords: changes in land use; local analysis; shift-share.

Resumen: El objetivo del estudio es analizar los cambios en el uso del suelo en el municipio de Assis Chateaubriand, Paraná, de 1985 a 2017, utilizando el modelo de distribución de turnos. La colonización del municipio de Assis Chateaubriand estuvo conformada por diferentes intereses que permitieron su colonización, entre ellos, el uso de recursos naturales, como el uso del suelo. Para llevar a cabo el estudio, se utilizaron el modelo de turno compartido, el procesamiento de imágenes y la evaluación cualitativa del paisaje. Entre los resultados identificados, se identificaron pocos cambios en el uso de la tierra, manteniendo el predominio del uso de la tierra agrícola. Sin embargo, los cambios en la producción agrícola han cambiado con el tiempo; hoy en día, hay un predominio de cultivos temporales, lo que permitió la homogeneización del paisaje.

Palabras clave: cambios en el uso del suelo; análisis local; shift-share. 


\section{INTRODUÇÃO}

O município de Assis Chateaubriand está localizado na Região Oeste do Paraná, tendo sido criado em 1966. Neste período inicial de colonização do município, a principal atividade econômica era primária, com predominância agrícola com grande uso de mão de obra, devido à baixa mecanização da produção. Foi essa característica que, inicialmente, possibilitou que as pessoas que chegaram ao município pudessem ser alocadas no espaço rural e ter renda para ali se manterem. Assim, o processo de formação do município propiciou a alteração da paisagem natural na área a partir da intervenção humana no meio ambiente, orientada pelos objetivos que a sociedade local do período estabeleceu. Nesse movimento, vê-se que a vegetação densa, característica do bioma Mata Atlântica, foi suprimida e substituída a partir da ocupação humana e da produção econômica desenvolvida em ciclos relacionados à produção rural.

Isso resultou, com o passar dos anos, em áreas de vegetação natural cada vez menores, em razão da expansão das paisagens de produção agropecuária e urbanização, sendo que essas características da produção econômica e social do município se estabeleceram e têm perdurado no decorrer dos anos. Tendo em vista que o projeto urbanístico do local esteve associado a negociações agrícolas e imobiliárias, ambas são características vinculadas ao uso da terra. Além disso, a criação do município ocorreu em conjunto à expansão da fronteira agrícola do Oeste do Paraná na década de 1950, que tinha o objetivo de atender às demandas alimentares da Região Sudeste do país. E, ainda, a história da ocupação do território do município é marcada pela atração das pessoas, via divulgação dos recursos naturais disponíveis para aquisição, como terras férteis, que aumentavam a expectativa e esperança das pessoas em melhorar a sua qualidade de vida. Deste modo, o uso da terra é uma questão central para o município; por meio desse uso, ele se formou e desenvolveu suas características.

Os estudos realizados no município referem-se a questões vinculadas à saúde e a doenças epidemiológicas; meio ambiente tangente aos recursos hídricos; desenvolvimento econômico; e história e memória de sua colonização. Assim, não foram identificadas pesquisas referentes ao 
uso da terra, considerando a importância desse uso para o município e sua formação. O objetivo do estudo é analisar as mudanças no uso da terra no município de Assis Chateaubriand, Paraná, no período de 1985 a 2017, a partir do modelo shift-share.

\section{INFORMAÇÕES SOBRE O MUNICÍPIO}

A colonização do município de Assis Chateaubriand foi constituída de diferentes interesses. Dessa forma, exemplificam-se esses interesses a partir da colonizadora, para a qual interessava, prioritariamente, o fator econômico relacionado aos lucros decorrentes da comercialização das terras. Ao Estado do Paraná, interessava o desenvolvimento da política de povoamento e de segurança, considerando a proximidade da localização do município com a fronteira com o Paraguai. E, por fim, quanto às pessoas que adquiriram as propriedades comercializadas, a elas interessava a questão social e econômica, pois, para essas pessoas e suas famílias, a aquisição das terras criava a esperança de melhores condições nos aspectos citados a partir das atividades laborais que desenvolveriam nas propriedades (MARQUES, 2017). Desta forma, a atração das pessoas para o município, a partir da década de 1960, ocorreu pela esperança de adquirir terras que possibilitassem a melhoria da qualidade de vida da família a partir da produção rural.

Essa colonização foi realizada, no início deste processo, pela primeira corrente migratória que chegou ao município, essa de origem da Região Norte do país. Ela foi constituída de nordestinos e de mineiros que já haviam participado da colonização da Região Norte do estado do Paraná. Essas pessoas trouxeram com elas a cultura agrícola cafeeira para a região. A segunda corrente migratória que chegou ao município foi intitulada como sulista. Os sulistas trouxeram o costume de produzir lavouras brancas, como milho e feijão, bem como introduziram a produção animal no local (SOUTO MAIOR, 1996). Cabe indicar que tanto os cultivos de cafezais como os de milho e feijão demandavam um número significativo de trabalhadores rurais, pois eram empreendidos manualmente (RIPPEL, 2005).

Denota-se que o município foi criado em um período de transformações no processo produtivo rural, tendo em vista que, a partir da década de 1950, 
o Brasil foi incentivado a modificar seu processo produtivo agropecuário mediante a inserção do uso de tecnologias rurais (CHEN; FLAHERTY; ZHANG, 2012; BEINTEMA; STADS, 2011). Essa modernização agrícola ocorreu no mesmo período em que o país apresentava uma crescente urbanização e demandava um aumento na produção alimentar para o abastecimento dos grandes centros. Além disso, o mercado externo era atrativo para a comercialização e requeria que também fosse abastecido. Mediante esse contexto, a estrutura produtiva agropecuária brasileira precisou ser modificada de tal forma que possibilitasse a produção em larga escala de culturas alimentares específicas.

Não demorou, e o município de Assis Chateaubriand aderiu também ao movimento de modernização da produção agrícola que se espraiava pelo país - foi, inclusive, considerado um dos municípios pioneiros na mecanização agrícola do estado do Paraná (COSTA, 2013). Essa alteração resultou que fosse introduzida, no âmbito rural local, a produção do binômio soja/trigo. Tratava-se de cultivos mecanizados e que implicavam menor utilização de mão de obra, tal como ocorreu nos mais diversos municípios do estado do Paraná.

Entre as questões que influenciaram a substituição produtiva no espaço rural, estão: (i) o não financiamento, a partir de 1962, da produção cafeeira pelo governo e (ii) o aumento das facilidades creditícias para a intensificação da mecanização na área rural na década de 1970 (FERREIRA, 1985). Ocorreram também (iii) geadas sequenciais nos anos de 1969, 1972 e 1975, em um cenário considerado negativo para o espaço rural, especialmente para a economia cafeeira, haja vista que as geadas no estado do Paraná, em 1953 e 1955, anos considerados próximos ao período citado anteriormente, resultaram em danos de quebra de safra acima de 50\%. Essas geadas desmotivaram muitos produtores de café no estado. As demais geadas posteriores tiveram perdas superiores, e a geada de 1975 aniquilou a principal cultura produtiva do estado, o café, sendo ela considerada a "geada negra", devido ao seu impacto devastador. Isso influenciou os produtores aqueles que dispunham de reservas econômicas para tanto - a migrarem para outras culturas agrícolas (SERRA, 2010).

Consequentemente, essa substituição reduziu a necessidade de mão de obra na área rural. A junção da substituição da cultura agrícola com o uso 
de novas tecnologias resultou na negação de condições de subsistência às pessoas que não possuíam propriedades rurais ou que possuíam pequenas propriedades e não dispunham de capital para o investimento necessário para a tecnificação (LORENSETTI, 2017). O resultado dessas alterações no espaço rural foi a migração de agricultores locais para as regiões CentroOeste e Norte do país, com a esperança de aumentarem sua área produtiva em territórios ainda pouco habitados e com terras compráveis a preços acessíveis (OLIVEIRA, 2010). Ocorreu também outro deslocamento populacional, este para a Região Metropolitana de Curitiba, cuja economia se encontrava em expansão e com carência de mão de obra, apresentando-se então como uma região de oportunidades (RIPPEL, 2005). Para Santos e Ferrera de Lima (2015), aproximando-se da atualidade, pode-se observar que a economia do município tem baixa participação da indústria, ou seja, de uma economia urbana, com um perfil de desenvolvimento local que necessita de avanços para a geração de emprego e renda. Essas características são descritas pela paisagem que pode ser observada no decorrer dos anos, pelo registro de imagens, pelos elementos que ainda estão visíveis no município e, ainda, pela quantificação do uso da terra, realizada pelas instituições.

Assim, o processo de formação do município propiciou a alteração da paisagem natural na área, a partir da intervenção humana no meio ambiente orientada pelos objetivos que a sociedade local do período estabeleceu. Nesse movimento, vê-se que a vegetação densa, característica do bioma Mata Atlântica, presente na região, foi suprimida e substituída a partir da ocupação humana e da produção econômica desenvolvida em ciclos relacionados à produção rural. Isso resultou, com o passar dos anos, em áreas de vegetação natural cada vez menores, em razão da expansão das paisagens de produção agropecuária e urbanização, sendo que essas características da produção econômica e social do município se estabeleceram e têm perdurado no decorrer dos anos.

Depreende-se que se entende por paisagem o conjunto de formas visíveis aos indivíduos. A partir dela é possível representar as relações entre os homens e a natureza no decorrer do tempo. Assim, os elementos físicos, naturais e artificiais disponíveis em uma área constituem a sua paisagem, 
que pode transcender o tempo, possibilitando a interação do passado com o presente, por ser objeto de mudança (SANTOS, 2006). Cabe perceber que a paisagem não é constituída por completo de uma só vez. Ao longo do tempo, a paisagem utiliza o processo de substituição e de adição de elementos para ir se moldando de forma a representar a respectiva sociedade, pois segue as características de produção do momento vigente. Assim, a formação da paisagem ocorre pela permanência ou pela mudança de elementos no decorrer dos anos, a partir da funcionalidade ou não desses mesmos elementos. Em relação ao social, a paisagem representa as ações que a sociedade local desenvolveu no decorrer dos anos, incluindo a atualidade (SANTOS, 1988).

\section{METODOLOGIA}

O período de análise compreendeu o ano de 1985 a 2017, a partir de informações geradas pela MapBiomas (2019) e pelo IBGE (1970; 1995; 2017). Mediante as informações coletadas sobre o uso da terra, optou-se pelo uso do modelo shift-share, para identificação das transformações em seu uso no município. Essa técnica é muito utilizada em análises regionais (ROLIM, 1999). Foi utilizada por Shikida e Alves (2009), Botassio e Batista de Oliveira (2013) e Prestes e Bezerra (2019), por exemplo. Entre as possibilidades de seu uso, foram utilizados o Efeito Área, que foi decomposto nos Efeitos Escala (EE) e Substituição (ES). O EE estimou, nesta pesquisa, as alterações referentes a tamanho ou escala do uso da terra do município e uso da terra da produção agropecuária, que podem ter sido ampliados ou reduzidos. O ES identificou áreas que foram substituídas pela expansão de outros usos da terra (CARVALHO et al., 2017).

Assim sendo, o modelo shift-share pode ser expresso, por:

$$
A i 2-A i 1=(\alpha A i 1-A i 1)+(A i 2-\alpha A i 1)
$$

Em que: Ai2 - Ai1 é a variação da área, para uso da terra municipal ou uso da terra da produção agropecuária, entre o período de tempo T1 (1985) e T2 (2017); ( $\alpha$ Ai1 - Ai1) = EE; $($ Ai2 - $\alpha$ Ai1 $)=E S$. O EE é o resultado da multiplicação do coeficiente de variação $(\alpha)$ pela área de uso da terra do 
ano de análise inicial (Ai1), subtraindo-se, deste resultado, a mesma área inicial. O ES é o resultado da subtração da área de uso da terra do ano de análise final (Ai2) pelo resultado da multiplicação do coeficiente de variação e a área de uso da terra do período inicial. Em ambos os casos, a área analisada é específica para cada categoria de uso da terra. O coeficiente de variação $(\alpha)$ é o resultado da razão entre a área total de uso da terra do ano final pelo ano inicial, do recorte temporal determinado (FAGUNDES; BORGES, 2015; CARVALHO et al., 2017).

Depreende-se que valores positivos e negativos do EE significam, nesta ordem, tendências de expansão ou redução do uso da terra analisado. Assim, os valores de EE indicam como seria o comportamento do uso da terra, no caso da pesquisa; se o aumento ou a redução da área ocorre de forma uniforme entre as categorias de uso (SANTOS; FARIA; TEIXEIRA, 2008). O ES, quando tem resultado positivo, indica a ocupação de áreas de outros usos da terra por aquele uso analisado. Caso o resultado seja negativo, indica que o uso da terra analisado teve áreas substituídas por outros usos. Além disso, no ES, o resultado entre adição dos valores de cada categoria de uso da terra deve ser igual a zero, isso tendo em vista que, neste modelo, as áreas substituídas são ocupadas proporcionalmente por aqueles usos da terra que se expandiram (LOURENZANI; CALDAS, 2014).

Depois disso, foram identificadas as características referentes ao uso da terra da atualidade, a partir do uso de geotecnologias. Para isso, foi utilizada imagem do sensor Landsat 8 - órbita ponto 223/077, datada de 23 de junho de 2018, com ausência de nuvens. Na sequência, foi realizada a classificação de imagem, em que se utilizou a classificação não supervisionada, com uso do algoritmo ISODATA, ou seja, esse algoritmo agrupou os pixels (Ponto Imageado pelo Sensor) da imagem conforme suas características espectrais, proporcionando a formação de clusters.

Essa classificação foi realizada com auxílio do software ENVI versão 5.5, Harris Geospatial Solutions Inc., licenciado para a Universidade Federal da Grande Dourados (UFGD). Posteriormente, realizou-se o processamento da imagem a partir das bandas espectrais (energia refletida em faixas), 2 (comprimento de onda: 450-510nm), 3 (comprimento de onda: 530$590 \mathrm{~nm}$ ), 4 (comprimento de onda: 640-670nm), 5 (comprimento de onda: 
850-880nm), 6 (comprimento de onda: 1570-1650nm) e 7 (comprimento de onda: 2110-2290nm). A imagem do uso da terra foi confeccionada a partir do uso do software Arcmap (ArcGis) Esri ${ }^{\circledR}$ versão 10.6.

Por fim, realizou-se a avaliação da paisagem da área rural do município, utilizando-se o fluxo de prestação de serviços ecossistêmicos relacionados ao uso da terra (Quadro 1). 


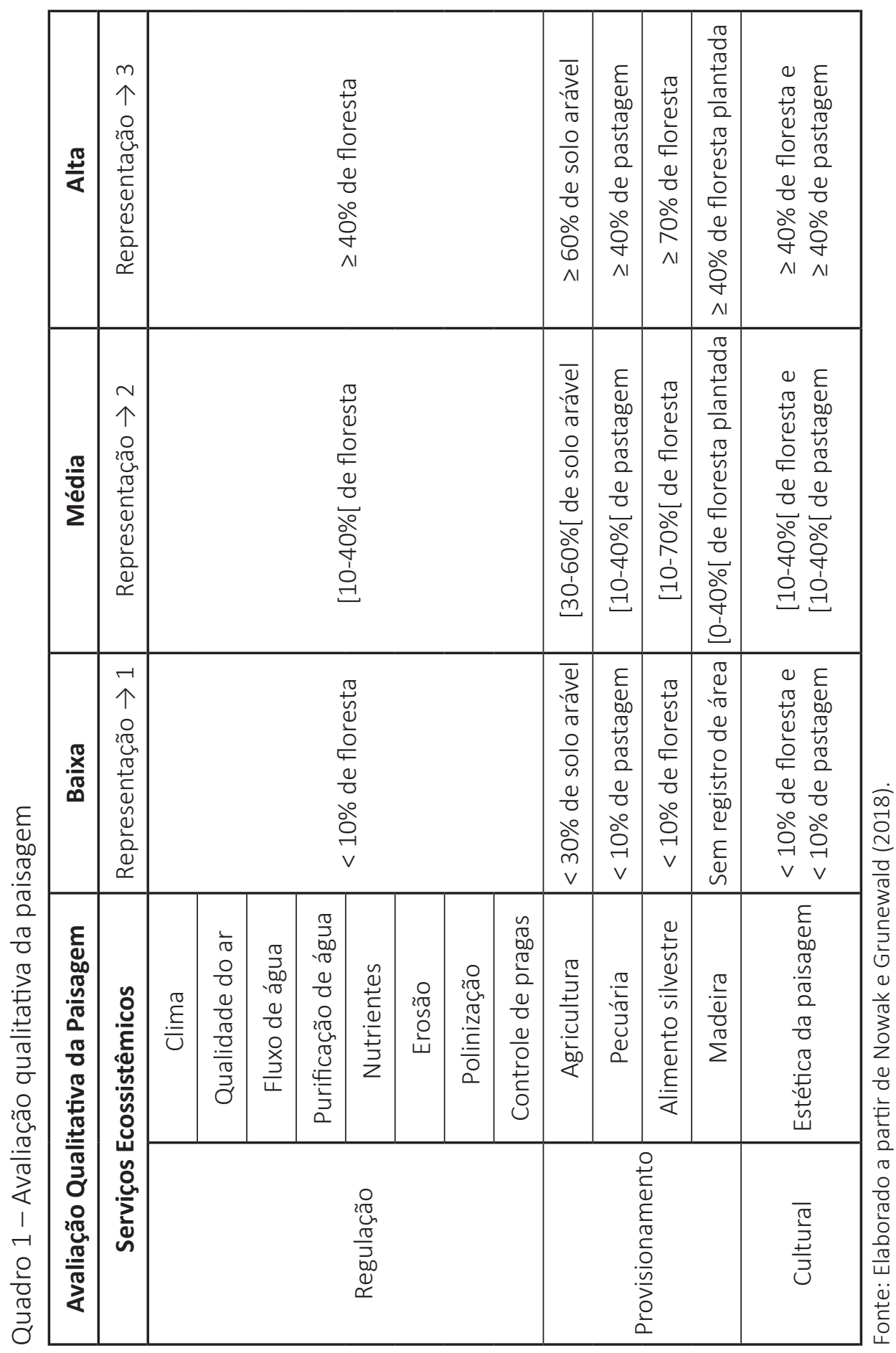


Observa-se que a metodologia foi utilizada anteriormente por Nowak e Grunewald (2018). A composição da avaliação considerou os serviços prestados pela natureza que puderam ser identificados nas áreas estudadas pelos autores e adequados para esta pesquisa. Como pode ser observado, o quadro é composto por diferentes serviços ecossistêmicos e por três classificações qualitativas da paisagem, que utilizam como critério o percentual de uso da terra destinado a situações específicas, como floresta, solo arável e pastagem.

\section{RESULTADOS E DISCUSSÃO}

Os indicadores do Efeito Escala (EE) e do Efeito Substituição (ES), a partir do modelo shift-share, possibilitaram identificar a variação da área em relação a cada uso da terra no município, no período de 1987 a 2017. Em relação ao EE, denota-se que seu comportamento foi distinto conforme o período analisado, sendo positivo de 1987-1997, indicando expansão total de 9,2 hectares de terra. O ES revela quais foram os usos da terra que cederam ou absorveram terras no período de análise. No período de 1987-1997, a categoria Floresta ampliou o seu uso da terra (514,3 hectares), enquanto as demais reduziram o seu tamanho, sendo que a maior redução no uso da terra ocorreu na categoria Agropecuária (449,2 hectares) (Tabela 1$)$.

Tabela 1 - Decomposição do Efeito Área em Efeito Escala (EE) e em Efeito Substituição (ES) no período de 1987-1997 - Uso da terra no município

\begin{tabular}{|c|c|c|c|c|c|c|}
\hline \multicolumn{2}{|c|}{ Uso da terra no município - Ano } & \multicolumn{2}{|c|}{$\begin{array}{c}\text { ariação da área } \\
(\mathbf{1 9 8 7 - 1 9 9 7 )}\end{array}$} & $\begin{array}{c}\text { EE } \\
\text { (1987-1997) }\end{array}$ & $\begin{array}{c}\text { ES } \\
\text { (1987-1997) }\end{array}$ \\
\hline & 1987 & 1997 & $($ ha) & $(\%)$ & $($ ha) & (ha) \\
\hline Floresta & $2.255,9$ & $2.770,4$ & 514,6 & 22,8 & 0,2 & 514,3 \\
Agropecuária & $93.838,6$ & $93.398,0$ & $-440,0$ & $-0,5$ & 8,9 & $-449,2$ \\
Corpo d'água & 283,6 & 275,1 & $-8,5$ & $-3,0$ & 0 & $-8,5$ \\
Área urbana & 538,2 & 481,6 & $-56,6$ & $-10,5$ & 0,1 & $-56,6$ \\
\hline Total & $96.916,3$ & $96.925,1$ & \multicolumn{5}{|l}{} \\
\hline
\end{tabular}

Fonte: Elaborado a partir MapBiomas (2019). 
Na Tabela 2, entre 1997-2007, o EE foi negativo, indicando retração de 166,7 hectares de terra. Em relação ao ES, em 1997-2007, a categoria Agropecuária reduziu a sua área (1.694 hectares), enquanto as demais categorias absorveram os hectares cedidos, tendo a categoria Floresta provocado a principal absorção (48,3\%) (1.344,3 hectares).

Tabela 2 - Decomposição do Efeito Área em Efeito Escala (EE) e em Efeito Substituição (ES) no período de 1997-2007 - uso da terra no município

\begin{tabular}{|c|c|c|c|c|c|c|}
\hline \multicolumn{3}{|c|}{ Uso da terra no município - Ano } & \multicolumn{2}{|c|}{$\begin{array}{c}\text { Variação da área } \\
(1997-2007)\end{array}$} & \multicolumn{2}{|c|}{$\begin{array}{cc}\text { EE } & \text { ES } \\
(1997-2007) & (1997-2007) \\
\end{array}$} \\
\hline & 1997 & 2007 & (ha) & $(\%)$ & (ha) & (ha) \\
\hline Floresta & $2.770,4$ & $4.109,9$ & $1.339,5$ & 48,3 & $-4,8$ & $1.344,3$ \\
\hline Agropecuária & $93.398,0$ & $91.543,7$ & $-1.854,6$ & $-2,0$ & $-160,6$ & $-1.694,0$ \\
\hline Corpo d'água & 275,1 & 285,4 & 10,3 & 3,8 & $-0,5$ & 10,8 \\
\hline Área urbana & 481,6 & 819,8 & 338,1 & 70,2 & $-0,8$ & 338,9 \\
\hline Total & $96.925,1$ & $96.758,8$ & & & & \\
\hline
\end{tabular}

Fonte: Elaborado a partir de MapBiomas (2019).

Por fim, entre 2007-2017, o comportamento do EE retornou a ser positivo, voltando a expandir 10,3 hectares. A principal variação de uso do EE está na categoria Agropecuária. Esses comportamentos indicam mudanças no uso da terra no município no decorrer dos anos analisados. Há de se lembrar aqui que a maioria dos hectares utilizados no município tem finalidades agropecuárias desde a década de 1970. Possivelmente, por esse motivo, ocorra uma maior variação nessa categoria, pois o uso pode ter sido alterado conforme o mercado de comercialização de produtos agropecuários. Em relação ao ES do período de 2007-2017, novamente a categoria Agropecuária reduziu a sua área (1.986,1 hectares) e novamente em razão da absorção, principalmente, pela categoria Floresta (1.752,5 hectares) (Tabela 3). O uso da terra na categoria Floresta pode estar relacionado à atividade econômica rural de produção vegetal, para a confecção de produtos em que a matéria-prima é a celulose, bem como pode referir-se a áreas de conservação ambiental. 
Tabela 3 - Decomposição do Efeito Área em Efeito Escala (EE) e em Efeito Substituição (ES) no período de 2007-2017 - uso da terra no município

\begin{tabular}{|c|c|c|c|c|c|c|}
\hline \multicolumn{3}{|c|}{ Uso da terra no município - Ano } & \multicolumn{2}{|c|}{$\begin{array}{c}\text { Variação } \\
\text { da área } \\
\text { (2007-2017) }\end{array}$} & \multirow{2}{*}{$\begin{array}{c}\text { EE } \\
(2007-2017) \\
\text { (ha) }\end{array}$} & \multirow{2}{*}{$\begin{array}{c}\text { ES } \\
(2007-2017) \\
\text { (ha) }\end{array}$} \\
\hline & 2007 & 2017 & (ha) & $(\%)$ & & \\
\hline Floresta & $4.109,9$ & $5.862,8$ & $1.752,9$ & 42,6 & 0,4 & $1.752,5$ \\
\hline Agropecuária & $91.543,7$ & $89.567,4$ & $-1.976,3$ & $-2,2$ & 9,8 & $-1.986,1$ \\
\hline Corpo d'água & 285,4 & 320,2 & 34,8 & 12,2 & 0 & 34,7 \\
\hline Área urbana & 819,8 & $1.018,7$ & 199,0 & 24,3 & 0,1 & 198,9 \\
\hline Total & $96.758,8$ & $96.769,1$ & & & & \\
\hline
\end{tabular}

Fonte: Elaborado a partir de MapBiomas (2019).

Utilizando os indicadores EE e ES, foram analisadas as especificidades do uso da terra do rural de Assis Chateaubriand no período de 1970-2017 (Tabela 4), de forma a compreender melhor este processo de mudanças no espaço rural do município. Em relação ao EE, ocorre que, no primeiro período de 1970-1995, o comportamento indicou a expansão de 1.638,9 hectares de terra. O uso da terra com finalidades da produção de culturas agrícolas temporárias foi responsável por $64 \%$ dessa alteração. Já no segundo período, o de 1995-2017, visualiza-se a redução de 11.117 hectares, em que se destaca novamente o uso da terra para produção de cultura temporária, representada por $84 \%$ da alteração, seguida de pastagem plantada, representada por $10 \%$ do total.

No tocante ao ES, ocorreu a identificação de que a atração de terras para a substituição, entre 1970-1995, referiu-se ao plantio de culturas temporárias (95\% dos hectares de terra) e matas e florestas plantadas (5\% dos hectares de terra substituídos). Para que houvesse essa substituição, foram reduzidos, principalmente, os usos de terra com o plantio de culturas agrícolas permanentes (53\% dos hectares cedidos), matas e florestas naturais (39\% dos hectares cedidos) e terras produtivas não utilizadas (6\% dos hectares cedidos). As mudanças realizadas no período de 1970-1995 indicam as transformações no uso da terra rural do município, com finalidades para $\mathrm{o}$ atendimento de mercado interno e externo, tendo em vista que o Brasil 
se destaca em relação à exportação de commodities que são classificadas como culturas temporárias.

Tabela 4 - Decomposição do Efeito Área em Efeito Escala (EE) e Efeito Substituição (ES) no período de 1970-2017 - uso da terra rural

\begin{tabular}{|c|c|c|c|c|c|c|}
\hline \multicolumn{3}{|c|}{ Uso da terra rural - Ano } & \multicolumn{2}{|c|}{$\begin{array}{l}\text { Variação da } \\
\text { área (1970- } \\
\text { 1995) }\end{array}$} & \multirow{2}{*}{$\begin{array}{c}\text { EE } \\
(1970- \\
1995) \\
(h a) \\
\end{array}$} & \multirow{2}{*}{$\begin{array}{c}\text { ES } \\
(1970- \\
1995) \\
\text { (ha) } \\
\end{array}$} \\
\hline & 1970 & 1995 & (ha) & (\%) & & \\
\hline Permanente & 10.263 & 385 & -9.878 & $-96,2$ & 194,6 & $-10.072,6$ \\
\hline Temporária & 55.024 & 74.182 & 19.158 & 34,8 & $1.043,2$ & $18.114,8$ \\
\hline Pastagem natural & 698 & 602 & -96 & $-13,7$ & 13,2 & $-109,2$ \\
\hline Pastagem plantada & 9.008 & 8.959 & -49 & $-0,5$ & 170,8 & $-219,8$ \\
\hline Matas e florestas naturais & 9.678 & 2.437 & -7.241 & $-74,8$ & 183,5 & $-7.424,5$ \\
\hline Matas e florestas plantadas & 105 & 994 & 889 & 846,7 & 1,9 & 887,0 \\
\hline Terras produtivas não utilizadas & 1.671 & 527 & -1.144 & $-68,7$ & 31,7 & $-1.175,7$ \\
\hline Total & 86.447 & 88.086 & & & & \\
\hline \multicolumn{3}{|c|}{ Uso da terra rural - Ano } & \multicolumn{2}{|c|}{$\begin{array}{l}\text { Variação da } \\
\text { área (1995- } \\
\text { 2017) }\end{array}$} & $\begin{array}{c}\text { EE } \\
(1995- \\
2017)\end{array}$ & $\begin{array}{c}\text { ES } \\
(1995- \\
2017)\end{array}$ \\
\hline & 1995 & 2017 & (ha) & (\%) & (ha) & (ha) \\
\hline Permanente & 385 & 55 & -10.208 & $-99,5$ & $-48,6$ & $-281,4$ \\
\hline Temporária & 74.182 & 67.684 & 12.660 & 23,0 & $-9.362,2$ & $2.864,2$ \\
\hline Pastagem natural & 602 & 1.197 & 499 & 71,5 & $-76,0$ & 671,0 \\
\hline Pastagem plantada & 8.959 & 1.315 & -7.693 & $-85,4$ & $-1.130,7$ & $-6.513,3$ \\
\hline Matas e florestas naturais & 2.437 & 6.464 & -3.214 & $-33,2$ & $-307,6$ & $4.334,6$ \\
\hline Matas e florestas plantadas & 994 & 254 & 149 & 141,9 & $-125,4$ & $-614,6$ \\
\hline Terras produtivas não utilizadas & 527 & 0 & -1.671 & $-100,0$ & $-66,5$ & $-460,5$ \\
\hline Total & 88.086 & 76.969 & & & & \\
\hline
\end{tabular}

Fonte: Elaborado a partir de IBGE (1970; 1995; 2017).

Na segunda análise referente ao período, 1995-2017, os usos que atraíram áreas foram o plantio de culturas agrícolas temporárias (36,4\% dos hectares substituídos), matas e florestas naturais (55,1\% dos hectares substituídos) e pastagem natural (8,5\% dos hectares substituídos). Nesse contexto, Matas e Florestas naturais foi a categoria responsável pela maior atração 
para a de uso da terra. Isso indica que as políticas públicas ambientais para o espaço rural têm influenciado o uso da terra no município, como o Código Florestal. A principal redução no uso da terra esteve na categoria Pastagem Plantada (83\% das áreas cedidas para a substituição). Esta redução indica que houve alterações no processo produtivo do município, ao qual pode ter sido reduzida a produção animal em benefício da produção de culturas vegetais.

Em relação à produção agropecuária, o Zoneamento EcológicoEconômico do Estado do Paraná (INSTITUTO ÁGUA E TERRA, 2015) deixa claro que não se encontram restrições significativas para a região em relação à produção agrícola, pelo contrário, esta é incentivada, incluindo a expansão da produção animal na região. O documento considera que a Zona 11 é aquela em que o município de Assis Chateaubriand está incluído, e sobre ela relata-se que,

[...] não apresenta restrições significativas para a produção agrícola, devido ao predomínio de baixa fragilidade geoambiental em relação aos relevos de baixa declividade e solos bem desenvolvidos [...] apresenta potencialidade para agricultura intensiva de grãos em função da alta aptidão agrícola e crescimento da atividade agroindustrial e de equipamentos agrícolas [...] As diretrizes preferenciais vinculam-se a manutenção e melhoramento da agricultura intensiva de grãos, inclusive com desenvolvimento das técnicas da agricultura de precisão na pequena propriedade, ampliação das atividades agroindustriais e indústria de equipamentos agrícolas; expansão da avicultura e suinocultura; expansão da indústria de processamento de carnes; implementação de políticas de incentivo ao turismo em áreas específicas; e incentivo à atividades de alto valor adicionado por meio da utilização do capital humano existente (INSTITUTO ÁGUA E TERRA, 2015, p. 233).

Após essas análises referentes às alterações que foram realizadas no uso da terra do município, optou-se por verificar de forma imagética o uso da terra na atualidade. Para isso, foi necessário identificar os valores referentes ao uso da terra e realizar análise de imagens de satélite. Em 2018, o uso da terra do município de Assis Chateaubriand foi identificado como sendo composto por categorias de análise i) Agropecuária, ii) Área Urbana, iii) Corpo d'Água. iv) Solo Exposto e v) Vegetação Natural, conforme exposto na Tabela 5. 
Percebe-se que foi acrescida, nesta análise, comparando-se às informações obtidas no MapBiomas (2019), a categoria Solo Exposto. Essa informação é o resultado da análise do processamento da imagem referente ao mês de junho de 2018. No caso, a existência de solo exposto no município pode ser resultado da colheita do chamado milho safrinha, colheita geralmente realizada entre os meses de abril e junho de cada ano (PEREIRA FILHO, 2015).

Tabela 5 - Distribuição do uso da terra, no município de Assis Chateaubriand $-2018$

\begin{tabular}{|lcc|}
\hline \multicolumn{1}{|c}{ Classe de uso da terra } & Quantidade de hectares & $\%$ \\
\hline Agropecuária (agricultura, pecuária & 59.420 & 61,5 \\
e florestal) & 1.509 & 1,6 \\
Área urbana & 3.253 & 3,4 \\
Corpo d'água & 23.290 & 24,0 \\
Solo exposto & 9.143 & 9,5 \\
Vegetação natural & 96.615 & 100 \\
\hline Total & & \\
\hline
\end{tabular}

Fonte: IPARDES (2018).

Na sequência, a Figura 1 representa o uso da terra do município de análise em 2018. 
Figura 1 - Uso da terra do município de Assis Chateaubriand, Paraná - 2018
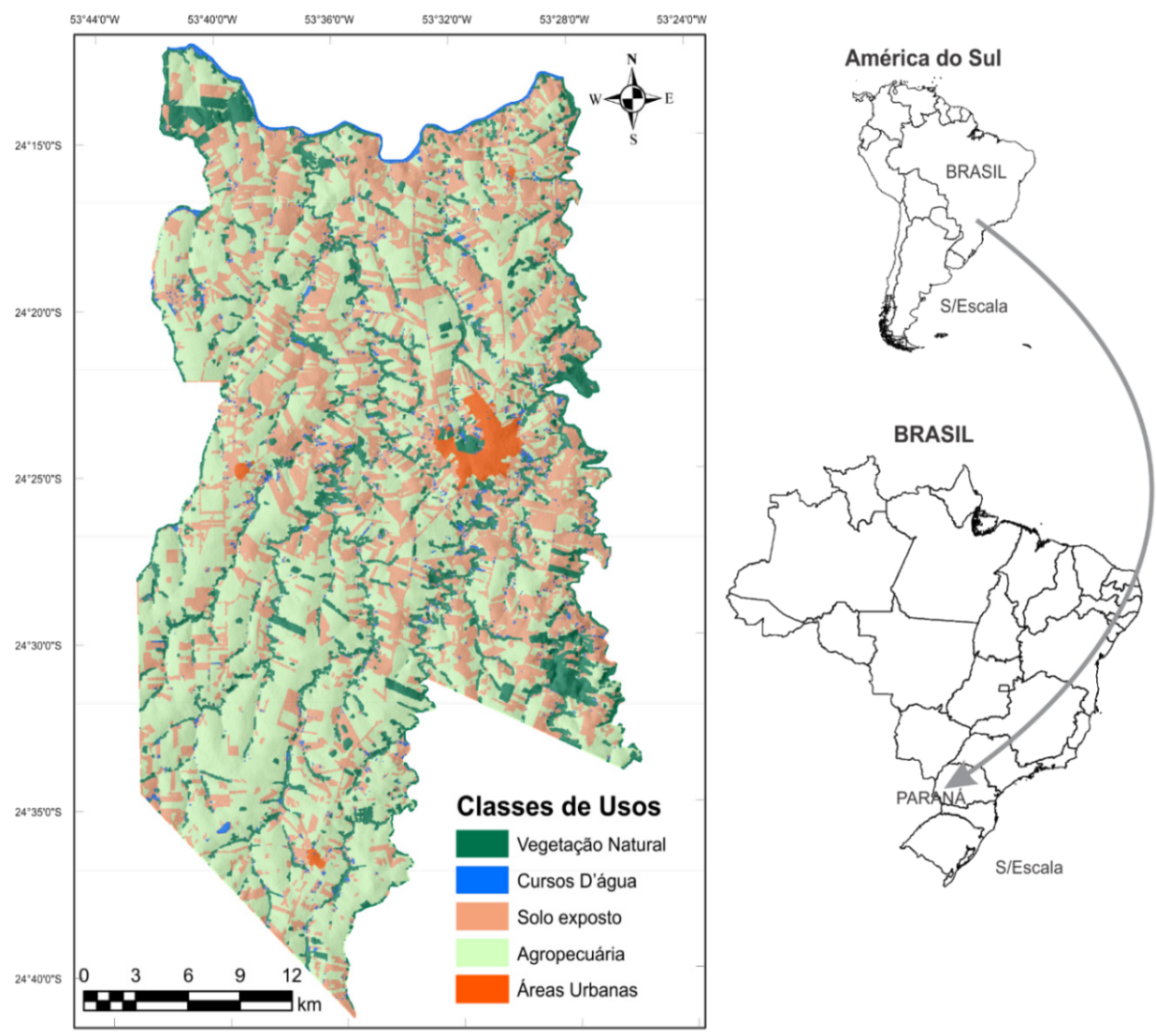

Fonte: Elaborado a partir de arquivos vetoriais obtidos no IBGE (2015).

Como indicado anteriormente, é visível o uso predominante da terra no município com finalidade da categoria Agropecuária. Vale dizer que são predominantes as áreas em que houve a substituição da cobertura vegetal natural com finalidades de produção rural. Tal medida tem consequências ambientais específicas para o bioma local. No caso, o bioma Mata Atlântica pode ser caracterizado como uma floresta tropical. Dessa forma, ao ser realizada a substituição da cobertura lenhosa por área agrária, como é o caso do município, são provocados efeitos negativos no clima, nas reservas de carbono do solo, nos recursos hídricos e na biodiversidade (SIBANDA et al., 2016). As mudanças ocorridas no uso da terra podem ter afetado os serviços 
ecossistêmicos locais originais, referentes à produção de alimentos, energia vegetal, água, plantas ornamentais e medicinais, condizentes com o bioma (PULLANIKKATIL et al., 2016). Pode ser observado que, entre a categoria Agropecuária, o processo produtivo predominante no município refere-se a culturas temporárias; em 2017, 48\% das terras com esta finalidade foram ocupadas com a produção de soja e milho (IBGE, 2020), sendo possível identificar homogeneidade produtiva no espaço rural.

Nesse contexto, como um adicional às análises realizadas, foi proposta a análise qualitativa da paisagem rural (Tabela 6) a partir da metodologia desenvolvida por Nowak e Grunewald (2018) e adaptada para o contexto do município de Assis Chateaubriand, ao qual sua análise é realizada a partir do uso da terra. Por essa análise, pode-se observar que, no município, há altos fluxos de serviços ecossistêmicos de provisionamento específico para a produção agrícola nos diferentes anos de análise, isso representado pelo valor 3. E, em relação aos demais serviços, eles são considerados baixos fluxos, representados pelo valor 1 , o que reforça a compreensão de que a paisagem é homogênea e que concentra o uso da terra nas práticas agrícolas.

Tabela 6 - Avaliação Qualitativa da Paisagem

\begin{tabular}{|llllll|}
\hline Avaliação Qualitativa da Paisagem & $\mathbf{1 9 8 7}$ & $\mathbf{1 9 9 7}$ & $\mathbf{2 0 0 7}$ & $\mathbf{2 0 1 7}$ \\
& Serviços Ecossistêmicos & & & & \\
\hline & Clima & 1 & 1 & 1 & 1 \\
& Qualidade do ar & 1 & 1 & 1 & 1 \\
& Fluxo de água & 1 & 1 & 1 & 1 \\
& Purificação de água & 1 & 1 & 1 & 1 \\
& Nutrientes & 1 & 1 & 1 & 1 \\
& Erosão & 1 & 1 & 1 & 1 \\
& Polinização & 1 & 1 & 1 & 1 \\
& Controle de pragas & 1 & 1 & 1 & 1 \\
& Agricultura & 3 & 3 & 3 & 3 \\
& Pecuária & 1 & 1 & 1 & 1 \\
Provisionamento & Alimento silvestre & 1 & 1 & 1 & 1 \\
& Madeira & 1 & 1 & 1 & 1 \\
& Estética da paisagem & 1 & 1 & 1 & 1 \\
\hline
\end{tabular}

Fonte: Elaborado a partir de Nowak e Grunewald (2018); MapBiomas (2019). 
Observa-se que a variedade no uso da terra é mais favorável à sustentabilidade da paisagem do que à homogeneidade (PALOMO et al., 2014), contudo ainda é desconhecida a estimativa de valor referente à heterogeneidade desejada (BLASCHKE, 2006). Tendo em vista que a diversidade espacial aumenta a possibilidade de preservação de habitats (BIGGS et al., 2012), bem como a existência de número maior de espécies e de processos ecossistêmicos (NOWAK; GRUNEWALD, 2018), então os resultados identificados tendem a implicar, para o município, perdas no âmbito da biodiversidade, no decorrer de seu processo de colonização; ou seja, a redução de espécies vegetais e animais no decorrer de seu processo de substituição de vegetação natural.

\section{CONSIDERAÇÕES FINAIS}

A análise realizada possibilitou identificar as transformações ocorridas no uso da terra do município, entre os anos de 1985 e 2017. Aponta-se que, posteriormente ao desmatamento da área, não ocorreram muitas transformações no uso da terra do município durante o período analisado (1970 a 2017), tendo em vista que o uso da terra continua predominantemente agrícola. E, quando essas mudanças ocorreram, consistiram em alterações produtivas rurais, como a substituição de culturas permanentes por temporárias ou por reflorestamentos, como visto nos resultados da pesquisa. De tal modo decorreu o processo que, atualmente, a maior parte do território do município é ainda destinada à produção agrícola, como foi apontado. Foi possível verificar isso por meio dos dados históricos utilizados e pelo processamento de imagens que auxiliou na confirmação dessas características do uso da terra na atualidade, podendo-se, claramente, perceber que o padrão de uso agrícola se manteve.

Mediante essas informações, pode-se observar que a paisagem do local sofreu importantes modificações, principalmente em razão do processo de substituição da vegetação natural do território por culturas tecnicamente mais avançadas - commodities. Esta questão possibilita identificar que a paisagem do município é homogênea e retrata o uso da terra do município. Uma vez obtidas essas informações por meio da avaliação qualitativa da paisagem de Assis Chateaubriand, ficou evidenciado que o local detém uma paisagem 
pouco diversificada. Contudo foram identificadas outras alterações na área do município que ocorreram no decorrer dos anos e que estão relacionadas aos processos produtivos ali realizados. Essas alterações detectadas auxiliaram a responder ao segundo objetivo específico, de procurar apontar as alterações populacionais e fundiárias a partir da década de 1970.

\section{REFERÊNCIAS}

BEINTEMA, N. M.; STADS, G. J. Agricultural R\&D in the new millennium: progress for some, challenges for many - Food Policy Report. Washington, DC: IFPRI, 2011, p. 1-32.

BIGGS, R. et al. Toward principles for enhancing the resilience of ecosystem services. Annual Review of Environment and Resources, [s.I.], v. 37, n. 1, p. 421-48, 2012.

BLASCHKE, T. The role of the spatial dimension within the framework of sustainable landscapes and natural capital. Landscape Urban Planning, [s.I.], v. 75, n. 3-4, p. 198-226, 2006.

BOTASSIO, D. C.; OLIVEIRA, G. B. Decomposição dos índices de desenvolvimento humano e social da Microrregião de Foz do Iguaçu: uma aplicação da análise shift-share para 1991 e 2000. Revista Tecnologia e Sociedade, Curitiba, v. 9, n. 17, p. 134-54, 2013.

CARVALHO, F. S.; THOMPSON, K.N.N.; SÁ LIMA, W.A.; SANTOS, N.F.A.; MELO, M.R.S.; SOUZA, V.Q.; BORGES, L.S.; GUERREIRO, A.C. Dinâmica de uso da terra, no setor agropecuário, em Paragominas - PA. Agroecossistemas, Belém, v. 9, n. 2, p. 14863, 2017.

CHEN, K.; FLAHERTY, K.; ZHANG, Y. China: recent developments in agricultural R\&D -Food Policy Report. Washington, DC: IFPRI, 2012, p. 1-6.

COSTA, F. R. A noção de municípios periféricos: contradições e desigualdades no estado do Paraná. 2013. 215 f. Tese (Doutorado em Geografia) - Universidade Estadual de Maringá, Maringá, PR, 2013.

FAGUNDES, F. N.; BORGES, A. C. G. Dinâmica territorial agropecuária e utilização das terras atuais no Escritório de Desenvolvimento Rural (EDR) de São João da Boa Vista. Geosaberes, Fortaleza, v. 6, n. 2, p. 178-92, 2015.

FERREIRA, Y. N. Industrialização e urbanização no Paraná. Geografia, Londrina, v. 3, n. 3, p. 113-28, 1985. 
IBGE. Produção Agrícola Municipal [PAM]. Produção Agrícola Municipal. IBGE, Rio de Janeiro, 2020. Disponível em: https://sidra.ibge.gov.br/pesquisa/pam/tabelas. Acesso em: 15 set. 2020.

IBGE. Censo Agropecuário 2017. IBGE, Rio de Janeiro, 2017. Disponível em: https:// sidra.ibge.gov.br/pesquisa/censo-agropecuario/censo-agropecuario-2017. Acesso em: 10 dez. 2019.

IBGE. Censo Agropecuário. Rio de Janeiro: IBGE, 1995.

IBGE. Censo Agropecuário. Rio de Janeiro: IBGE, 1970.

INSTITUTO ÁGUA E TERRA [IAT]. Zoneamento Ecológico Econômico - ZEE. IAT, 2015. Disponível em: http://www.iat.pr.gov.br/Pagina/Zoneamento-EcologicoEconomico-ZEE. Acesso em: 11 nov. 2020.

INSTITUTO PARANAENSE DE DESENVOLVIMENTO ECONÔMICO E SOCIAL [IPARDES]. Base de dados do Estado. IPARDES, 2018. Disponível em: http://www.ipardes.gov. br/imp/index.php. Acesso em: 10 dez. 2020.

LORENSETTI, E. A relação da dinâmica populacional de Assis Chateaubriand com a modernização da agricultura e apropriação da terra. 2017. 108 f. Dissertação (Mestrado em Desenvolvimento Rural Sustentável) - Universidade Estadual do Oeste do Paraná, Marechal Cândido do Rondon, PR, 2017.

LOURENZANI, W. L.; CALDAS, M. M. Mudanças no uso da terra decorrentes da expansão da cultura da cana-de-açúcar na região oeste do estado de São Paulo. Ciência Rural, Santa Maria, v. 44, n. 11, p. 1980-7, 2014.

MAPBIOMAS. Estatísticas. Mapbiomas, [s.I.], 2019. Disponível em: https:// mapbiomas.org/estatisticas\#: :text=Aqui\%20voc\%C3\%AA\%20pode\%20 baixar\%20a,munic\%C3\%ADpio\%20de\%201985\%20a\%202019. Acesso em: 17 nov. 2019.

MARQUES, M. Narrativas orais de moradores do distrito de Bragantina, município de Assis Chateaubriand, Oeste do Paraná. História Oral, São Paulo, v. 20, n. 1, p. 169-90, 2017.

NOWAK, A.; GRUNEWALD, K. Landscape sustainability in terms of landscape services in rural areas: exemplified with a case study area in Poland. Ecological Indicators, [s.I.], v. 94, p. 12-22, 2018. 
OLIVEIRA, M. L. T. O professor PDE e os desafios da escola pública paranaense: produção didático-pedagógica. Curitiba: Secretaria Estadual de Educação do Paraná, 2010.

PALOMO, I.; MONTES, C.; MARTÍN-LÓPEZ, B.; GONZÁLEZ, J. A.; GARCÍA-LLORENTE, M.; ALCORLO, P.; GARCÍA MORA, M. R. Incorporating the social-ecological approach in protected areas in the anthropocene. Bioscience, [s.I.], v. 64, n. 3, p. 181-91, 2014.

PEREIRA FILHO, I. A. Cultivo do Milho. EMBRAPA, 2015. Disponível em: https:// www.spo.cnptia.embrapa.br/conteudo?p_p_id=conteudoportlet_WAR_siste masdeproducaolf6_1ga1ceportlet\&p_p_lifecycle=0\&p_p_state=normal\&p_p_ mode=view\&p_p_col_id=column-2\&p_p_col_count=1\&p_r_p_-76293187_sistem aProducaold=7905\&p_r_p_-996514994_topicold=8658. Acesso em: 10 jan. 2019.

PULLANIKKATIL, D.; PALAMULENO, L. G.; RUHIIGA, T. M. Land use/land cover change and implications for ecosystems services in the Likangala River Catchment, Malawi. Physics and Chemistry of the Earth, Parts A/B/C, [s.I.], v. 93, p. 96-103, 2016.

PRESTES, A. F.; BEZERRA, F. M. Desigualdade salarial entre gêneros: análise por setor e região do Paraná. Economia \& Região, Londrina, v. 7, n. 2, p. 29-46, 2019.

RIPPEL, R. Migração e desenvolvimento econômico no Oeste do Paraná: uma análise de 1950 a 2000. 2005. 261 f. Tese (Doutorado em Demografia) - Universidade Estadual de Campinas, Campinas, SP, 2005.

ROLIM, C. F. C. Reestruturação produtiva, mundialização e novas territorialidades: um novo programa para os cursos de economia regional e urbana. Curitiba: UFPR, 1999.

SANTOS, F. A. A.; FARIA, R. A.; TEIXEIRA, E. C. Mudança da composição agrícola em duas regiões de Minas Gerais. Revista de Economia e Sociologia Rural, Brasília, v. 46, n. 3, p. 579-95, 2008.

SANTOS, L. P. FERRERA DE LIMA, J. Desenvolvimento Econômico Local em Assis Chateaubriand-PR. Desenvolvimento Regional em Debate, Canoinhas, v. 5, n. 1, p. 180-200, 2015.

SANTOS, M. Metamorfoses do espaço habitado - fundamentos teóricos e metodológicos da geografia. São Paulo: Hucitec, 1988.

SANTOS, M. A natureza do espaço: técnica e tempo, razão e emoção. São Paulo: Editora da USP, 2006. 
SERRA, E. Conflitos rurais no Paraná: como foi que tudo começou. Boletim de Geografia, Maringá, v. 28, n. 1, p. 75-89, 2010.

SIBANDA, M.; DUBE, T.; MUBANGO, T.; SHOKO, C. The utility of earth observation technologies in understanding impacts of land reform in the eastern region of Zimbabwe. Journal of Land Use Science, [s.I.] , v. 11, n. 4, p. 384-400, 2016.

SHIKIDA, P. F. A.; ALVES, L. R. A. Panorama estrutural, dinâmica de crescimento e estratégias tecnológicas da agroindústria canavieira paranaense. Nova Economia, Belo Horizonte, v. 11, n. 2, 2009.

SOUTO MAIOR, L. História do município de Assis Chateaubriand: o encontro das correntes migratórias na última fronteira agrícola do estado do Paraná. Maringá: Clichetec, 1996. 
